\title{
PIELONEFRITIS XANTOGRANULOMATOSA DIFUSA CON FÍSTULA RENOCÓLICA INADVERTIDA DURANTE MÁS DE DOS AÑOS
}

\author{
L.A. FARIÑA PÉREZ, D. PESgUEIRA SANTIAGO, C. ÁlVAREZ ÁlVAREZ*, \\ E.R. ZUNGRI TELO
}

Servicio de Urología. *Servicio de Anatomía Patológica. Centro Médico POVISA. Vigo. Pontevedra.

Actas Urol Esp. 28 (7): 553-555, 2004

\section{RESUMEN}

PIELONEFRITIS XANTOGRANULOMATOSA DIFUSA CON FÍSTULA RENOCÓLICA INADVERTIDA DURANTE MÁS DE DOS AÑOS

INTRODUCCIÓN: Aunque la fístula renocólica es una complicación conocida de la forma difusa de la pielonefritis xantogranulomatosa, describimos un caso inusual, por la pobreza de los síntomas y la larga evolución de la enfermedad antes de ser diagnosticada.

CASO CLÍNICO: Una mujer de 75 años fue vista en el Servicio de Urgencias con fiebre y malestar general. El examen y las pruebas de laboratorio mostraron una masa en el hemiabdomen izquierdo y anemia, y en la radiografía de abdomen y la tomografia computarizada se encontró un cálculo grande así como una gruesa pielonefritis xantogranulomatosa con fistula renocólica. Una revisión de su historial médico mostró una radiografia de abdomen realizada más de dos años antes por su médico de familia, con el mismo cálculo y gas en la cavidad renal. Se le realizó nefrectomía, pancreatectomía caudal y colectomía parcial con buenos resultados.

COMENTARIO: La pielonefritis xantogranulomatosa es una forma infrecuente de infección crónica del riñón y de los espacios retroperitoneales. Este caso poco sintomático que destruyó el riñón e indujo una fístula renocólica, es inusual porque pasó inadvertido durante años a pesar de una manifestación clínica y radiológica bastante típica.

PALABRAS CLAVE: Pielonefritis xantogranulomatosa. Fístula renocólica.

\section{ABSTRACT \\ DIFFUSE XANTHOGRANULOMATOUS PYELONEPHRITIS WITH A RENOCOLIC FISTULA NEGLECTED FOR MORE THAN TWO YEARS}

INTRODUCTION: Although reno-colic fistula is a well-known complication of the diffuse form of xanthogranulomatous pyelonephritis, the features of the case here presented are unusual because of the paucity of symptoms and long lasting evolution of the disease before it was diagnosed.

CLINICAL CASE: A 75 year-old woman was seen at the emergency room complaining of fever and malaise. Physical and laboratory examination showed anemia and a left abdominal mass, and on X-ray and abdominal CT, a gross stone and huge left renal and extrarenal xanthogranulomatous pyelonephritis with renocolic fistula were disclosed. A review of her clinical record showed an X-ray performed two years before by the attending family clinician, with identical gross calculi and gas into the kidney. Nephrectomy, caudal pancreatectomy and partial colectomy were accomplished with good results.

COMMENT: This case of poor-symptomatic xanthogranulomatous pyelonephritis that destroyed the kidney and induced a renocolic fistula, is unusual because it was neglected for more than two years due to unawareness of the clinical and radiological picture.

KEY WORDS: Xanthogranulomatous pyelonephritis. Reno-colic fistula. 
A unque la fístula renocólica es una complicación conocida de la forma difusa de la pielonefritis xantogranulomatosa, las características de este caso lo hacen inusual por la pobreza de los síntomas y la larga evolución de la enfermedad antes de ser diagnosticada. En esta paciente, una pielonefritis xantogranulomatosa poco sintomática que destruyó el parénquima renal e indujo la formación de una fístula renocólica, pasó inadvertida durante más de dos años.

\section{CASO CLÍNICO}

Una mujer de 75 años fue vista en el Servicio de Urgencias con fiebre, dolor en el flanco izquierdo y malestar general. Tenía una historia médica de episodios repetidos de dolor de flanco y fiebre, habiendo sido diagnosticada de anemia crónica, litiasis urinaria e infección urinaria crónica por Proteus. No había notado neumaturia ni fecaluria. Una revisión de su historial médico mostró, en una radiografía de abdomen realizada más de dos años antes por su médico de familia, un grueso cálculo y gas en el interior del riñón izquierdo (Fig. 1). El examen y las pruebas de laboratorio mostraron una masa en el hemiabdomen izquierdo, móvil y poco dolorosa. Tenía anemia (hemoglobina $7,9 \mathrm{gr} / \mathrm{dl})$, leucocitosis $(20,1 \times 10 \mathrm{e} 9 /$ $\mathrm{mm} 3)$, trombocitosis $(520 \times 10 \mathrm{e} / \mathrm{mm} 3)$ y una creatinina de $1,5 \mathrm{mg} / \mathrm{dl}$. En el cultivo de orina creció E. coli. En la radiografia simple de abdomen y la tomografia computada se encontró el mismo cálculo grande en el lado izquierdo y otros menores a lo largo del uréter, aumento del tamaño del riñón izquierdo, que era afuncionante, tenía múltiples áreas abscesificadas rodeando el cálculo, extensión de la inflamación al espacio perinéfrico, y una comunicación entre el cálculo y el colon descendente. El enema opaco también reveló la fístula (Fig. 2). Estas imágenes sugirieron el diagnóstico de la forma difusa de pielonefritis xantogranulomatosa. Se le realizó una nefrectomía "radical" con resección en bloque del colon y la cola del páncreas enfermos, así como anastomosis término-terminal del intestino grueso (Fig. 3). Tuvo una recuperación buena y se encuentra bien después de dos años.

\section{COMENTARIO}

Aunque se han publicado más de dos mil casos de pielonefritis xantogranulomatosa en la

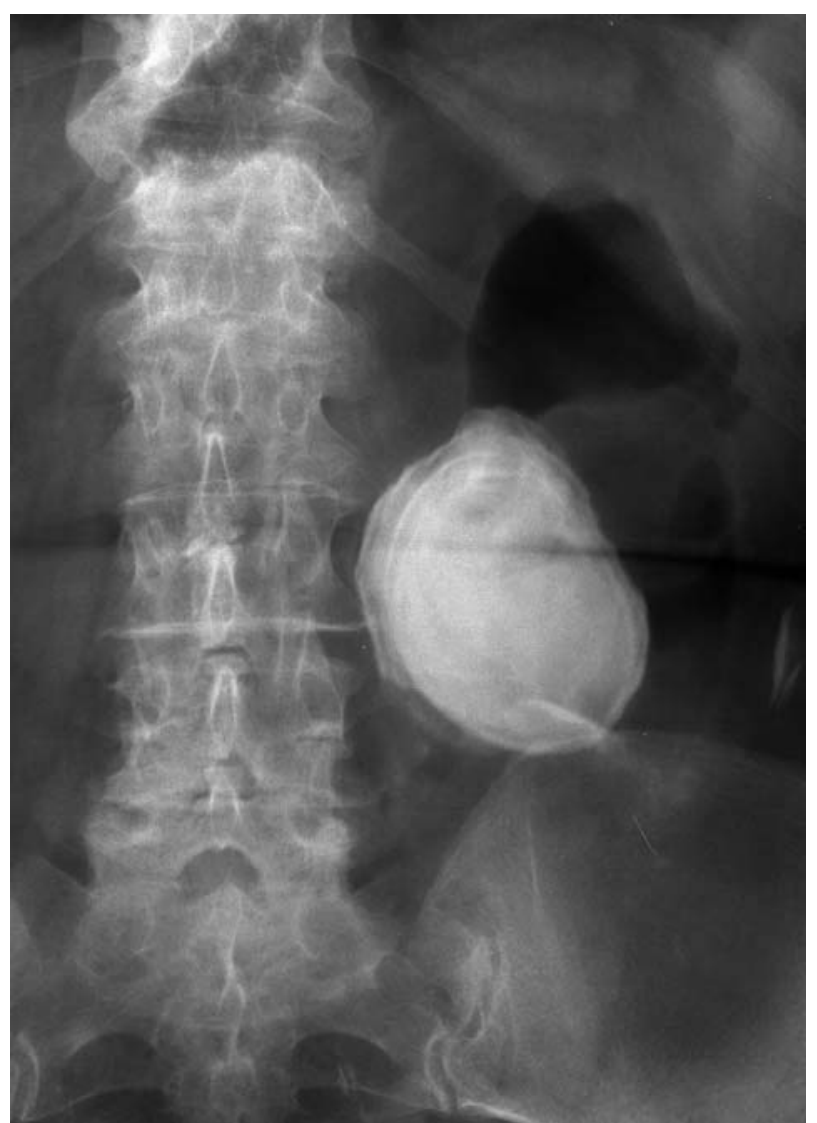

FIGURA 1. RX simple de abdomen: obsérvese el grueso cálculo renal izquierdo y por encima una imagen aérea que parece dibujar la pelvis y cálices renal.

bibliografía especializada, se trata de una forma infrecuente de infección crónica del riñón y de los espacios retroperitoneales, que sigue siendo poco conocida ${ }^{1,2}$. Puede afectar a ambos sexos y a cualquier edad, si bien el paciente típico es una mujer de mediana edad con infecciones urinarias crónicas. Probablemente es una forma especial de respuesta inflamatoria a la obstrucción urinaria crónica infectada, que da lugar a una destrucción ya sea focal o difusa del parénquima renal y de las estructuras vecinas, con un infiltrado inflamatorio agudo y crónico en el que pueden verse macrófagos cargados de lípidos y conteniendo inclusiones eosinófilas. La extensión extrarrenal a la pared abdominal, intestino, diafragma, músculo psoas y otras estructuras vecinas es típica de la forma difusa, y puede dar lugar a una variedad de fístulas con órganos abdominales y torácicos, o con la piel. 


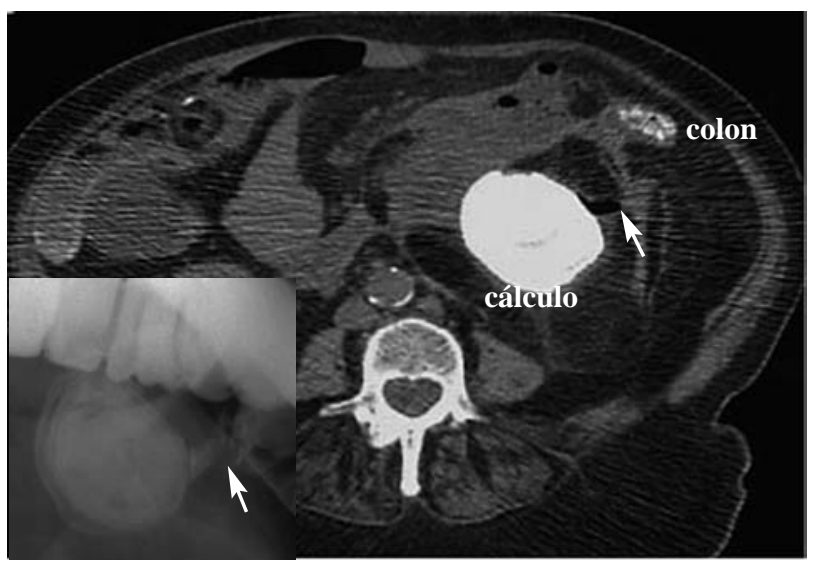

FIGURA 2. TC de abdomen: riñón izquierdo destruido por un proceso inflamatorio que se extiende por espacios perirenales. Existe gas dentro del riñón y hay una comunicación con el colon. La flecha señala la posible comunicación entre el cálculo y el colon. Abajo, enema opaco: fistula renocólica.

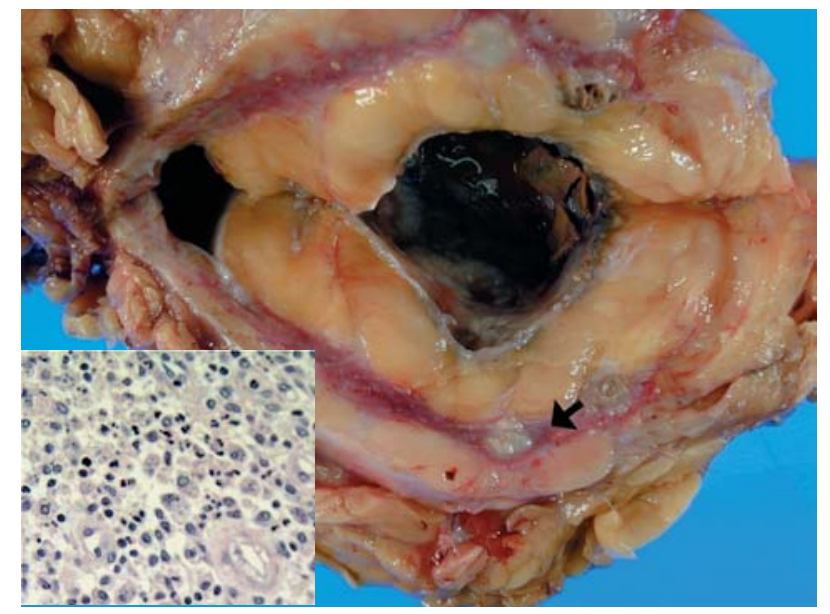

FIGURA 3. Examen macroscópico: nódulos amarillos de hasta $1 \mathrm{~cm}$ de diámetro que reemplazan la arquitectura renal (flecha). Abajo, examen microscópico: infiltrado inflamatorio granulomatoso con macrófagos cargados de lipidos, neutrófilos, linfocitos y células plasmáticas.

La presentación clínica es variable, siendo las quejas habituales la fiebre, una masa en el flanco y fatiga $u$ otros síntomas constitucionales. No siempre se diagnostica preoperatoriamente, y si hay una fístula a veces es difícil sospecharla ${ }^{3}$.
Puede ser indistinguible de un carcinoma por los datos clínicos, radiológicos o macroscópicos y, en algunos casos, se ha visto coincidencia de pielonefritis xantogranulomatosa y carcinoma transicional o de células renales. Sin embargo, el diagnóstico puede avanzarse con los hallazgos de la urografia y la tomografia computada ${ }^{4}$ : presencia de cálculo crónicamente obstructivo o coraliforme, aumento del tamaño renal con o sin hidronefrosis, riñón no funcionante, áreas inflamatorias de baja densidad distribuidas difusamente, $\mathrm{y}$ posible afectación extrarrenal. Debido a la posible implicación de varios órganos o vísceras, el tratamiento quirúrgico de la forma difusa es difícil y se necesita una evaluación completa previa de la extensión de la enfermedad.

En un paciente mayor con malestar general y síntomas crónicos del tramo urinario o litiasis antigua, es necesario tener en cuenta el posible diagnóstico de la forma difusa de pielonefritis granulomatosa.

\section{REFERENCIAS}

1. BALLESTEROS JJ.: Inusuales formas clínicas de presentación y asociaciones patológicas raras de la pielonefritis granulomatosa. Arch Esp Urol 2002; 55: $119-130$.

2. EASTHAM J, AHLERING T, SKINNER E.: Xanthogranulomatous pyelonephritis: clinical findings and surgical considerations. Urology 1994; 43: 295-299.

3. PARVEY HR, COCHRAN ST, PAYAN J, GOLDMAN S, SANDLER CM.: Renocolic fistulas: complementary roles of computed tomography and direct pyelography. Abdom Imaging 1997; 22: 96-99.

4. KIM JC.: US and CT findings of xanthogranulomatous pyelonephritis. Clin Imaging 2001; 25: 118121.

Dr. L.A. Fariña Pérez

Servicio de Urología. Centro Médico POVISA

C/ Salamanca, 5

36211 Vigo (Pontevedra)

(Trabajo recibido el 29 octubre de 2003) 